\title{
ISOINMUNIZACIÓN ANTIKELL: MANEJO CLÍNICO DE 26 CASOS
}

\author{
Onica Armijo S. ${ }^{1}$, María de la Calle F. ${ }^{1}$, Elena Martin B. ${ }^{1}$, Roberto Rodríguez G. ${ }^{1}$, Mar \\ González A. ${ }^{1}$, Francisco Herrero de L. ${ }^{1}$, Ana Rodríguez De la R. ${ }^{2}$, Antonio González G. ${ }^{1}$ \\ 1 Departamento de Ginecología y Obstetricia, ${ }^{2}$ Servicio de Hematología, Hospital La Paz, Madrid, España.
}

\section{RESUMEN}

La principal causa de anemia fetal es la isoinmunización Rh por el desarrollo de anticuerpos frente al antígeno D. La aloinmunización antiKell es una patología poco frecuente aunque puede producir un cuadro de anemia fetal muy grave. Su incidencia relativa ha aumentado en los últimos años debido al mayor número de transfusiones sanguíneas por disminución de la isoinmunización anti-D. Presentamos 26 casos de isoinmunización antiKell controlados en el Hospital La Paz de Madrid, durante los años 2003-2009 y una revisión de la literatura.

\section{PALABRAS CLAVE: Isoinmunización antiKell, transfusión intravascular, manejo clínico, embarazo}

\section{SUMMARY}

The main cause of fetal anemia is red-cell alloimmunization. Kell alloinmunization is a rare disease, although it can produce severe fetal damages. The relative incidence of antiKell isoinmunization has increased last years due to the blood transfusions has grown also, and anti-D aloinmunization has decreased. We report twenty six cases of pregnant women with isoinmunization antikell controlled in La Paz Hospital, Madrid, between 2003-2009 and a review of the literature.

KEY WORDS: AntiKell alloinmunization, intravascular transfusion, clinical management, pregnancy

\section{INTRODUCCIÓN}

Se han descrito más de 50 antícuerpos eritrocitarios denominados irregulares capaces de producir enfermedad hemolítica perinatal. El grupo sanguíneo Kell está formado por 24 antígenos, de los que destacan por su mayor inmunogenicidad y frecuencia el K (Kell1 o K1) y el k (Kell2, K2 o Cellano). Los individuos Kell positivos son los que tienen el antígeno K (KK ó Kk) y la mayoría son heterozigóticos (1). El $91 \%$ de la población de origen caucásico y el $98 \%$ de origen africano son negativos para el antígeno K (kk) (2). La isoinmuniza- ción antikell se produce cuando una persona que carece del antígeno $\mathrm{K}$, entra en contacto con el antígeno como ocurre en la hemorragia transplacentaria fetomaterna, transfusiones sanguíneas, transplantes de órganos y tejidos o intercambio de sangre y jeringas.

La anemia fetal generada por esta isoinmunización tiene un origen fisiopatológico similar al antiD, pero al que se suma en el primer trimestre la supresión de la eritropoyesis fetal. El antígeno Kell presenta una inmunogenicidad mucho menor que el antígeno responsable de la isoinmunización $\mathrm{Rh}$, lo que explica que sólo el $5 \%$ de las personas 
Kell negativas sometidas a transfusión incompatible desarrollen respuesta inmune con formación de anticuerpos $(3,4)$.

La gravedad de la isoinmunización se objetiva a través de la anemia fetal que se estima por la determinación del pico sistólico en la arteria cerebral media fetal (ACM). El título de anticuerpos antiKell maternos es orientativo en esta patología, sabiendo que titulaciones muy elevadas (>256) posiblemente desarrollen enfermedad grave y titulaciones muy bajas $(<32)$ enfermedad leve. Son las titulaciones intermedias las que pueden desarrollar una clínica más variable e impredecible $(5,6)$. Los tratamientos actuales de la isoinmunización grave consisten en las inmunoglobulinas intravenosas y la transfusión sanguínea fetal intrauterina.

El objetivo del presente estudio es presentar nuestra experiencia en el manejo de la mujer embarazada con positividad para los anticuerpos antiKell durante la gestación.

\section{PACIENTES Y MÉTODO}

Estudio retrospectivo de cohortes de 26 gestaciones complicadas con isoinmunizacion antiKell, controladas en el Servicio de Fisiopatolgía Fetal y en el Servicio de Hematología del hospital La Paz de Madrid, España, durante el periodo 2003-2009. Las variables estudiadas fueron: los títulos de anticuerpos con la gravedad de la afectación fetal, la necesidad de terapeútica previa al parto (administración de inmunoglobulinas, transfusión intrauterina) y el momento de finalización de la gestación.

Se analizó también las semanas de gestación en el momento del diagnóstico, el resultado perinatal (aborto, muerte fetal, parto normal, cesárea urgente o necesidad de inducción), y las complicaciones de la terapeútica.

Los estudios inmunohematológicos que se realizaron son la identificación de anticuerpos en la madre, utilizando técnicas que incluyan antiglobulinas, fenotipo materno Kell, estudio de titulación de anticuerpos mediante doble dilución sin utilizar medios potenciadores, incubación 60 minutos a $37^{\circ} \mathrm{C}$ y lectura de anti IgG, y estudio del fenotipo paterno con suero específico según indicaciones del fabricante.

En los casos en que el padre fuera heterozigoto se determina el fenotipo fetal mediante PCR, las secuencias de los genes que codifican los antígenos Kell en el ácido deoxirribonucleico (ADN) fetal libre en el plasma o suero materno, a partir de la $18^{\mathrm{a}}$ semana de gestación $(7,8,9)$.

Ante una gestación cuya madre ha desarrollado anticuerpos anti-Kell y el padre tenga antígeno Kell positivo, confirmado o sospechado, el seguimiento exhaustivo de la paciente se realizará en las consultas de alto riesgo de nuestro hospital, mediante monitorización ultrasónica para detectar signos de anemia (ascitis, derrame pericárdico, polihidramnios) y velocimetría doppler en ACM para cuantificar la anemia fetal y la necesidad de transfusión intrauterina (10).

En pacientes con títulos elevados de anticuerpos, en las que todavía no es posible técnicamente la transfusión intrauterina, por ser menor de 18-20 semanas de gestación, utilizamos la administración de gammaglobulina intravenosa $(1 \mathrm{~g} / \mathrm{kg}$ una vez por semana).

La transfusión intrauterina se indica si el feto es menor de 32 semanas, el hematocrito menor del $30 \%$ y el pico sistólico de velocidad en ACM está por encima de 1,5 MoM. Se transfunde concentrado de hematíes grupo O Rh negativo, Kell negativo, radiado las 24 horas previas, leucodepleccionados $y$ en fracciones de $10 \mathrm{ml}$ cada 2 minutos. El volumen a transfundir se planifica con la hemoglobina calculada por el estudio de velocimetría Doppler y se ajusta de manera definitiva con una muestra de sangre obtenida en el cordón al inicio de la transfusión.

Se considera isoinmunización leve cuando no hay necesidad de tratamiento prenatal, e isoinmunización grave cuando se requiere tratamiento prenatal. Los datos se analizaron mediante el programa SPSS9. La descripción de los datos cualitativos se realizó en forma de frecuencias absolutas y porcentajes.

\section{RESULTADOS}

Se diagnosticaron 26 casos de isoinmunización antikell: $62 \%$ durante el embarazo, $23 \%$ en el parto y $15 \%$ postaborto. El momento de la gestación en el que se produce el diagnóstico fue mayoritariamente entre el primer y segundo trimestre.

De los 26 casos el 58\% tenían parejas Kell negativa y por tanto sin necesidad de seguimiento (aunque a las 28-30 semanas de gestación se les hace un nuevo control por la posibilidad de que hubiera otra paternidad no comunicada). El $42 \%$ tenían una pareja Kell positiva, y fue en estas donde se determinó el fenotipo paterno.

Respecto a la causa de la isoinmunización, de las gestantes en las que encontramos anticuerpos antiKell y su pareja era Kell negativa, en todas ellas existía el antecedente de transfusión materna tras parto instrumental en la gestación previa o en una cirugía anterior: la mayoría desarrolló una isoinmunización leve, sin repercusión en el feto. Dos de 
ellas abortaron, aunque la causa de la interrupción de la gestación no puede atribuirse, casi con seguridad, a la generación de estos anticuerpos. En dos pacientes coexistía el antecedente transfusional y el hecho de que su pareja fuera Kell positiva. Con respecto al título de anticuerpos, de las isoinmunizaciones leves, el $85 \%$ tenían niveles por debajo o igual a 32 y un $15 \%$ por encima de este valor. En el $100 \%$ de las isoinmunizaciones graves tenían valores por encima de 256 al comienzo del segundo trimestre.

El estudio del gen Kell fetal en sangre materna periférica se realizó en tres casos ( disponemos de esta posibilidad desde hace pocos años) en un laboratorio de referencia: dos de los fetos fueron $\mathrm{K}$ positivos y en uno no se pudo obtener resultados. En un caso se realizó el estudio del fenotipo fetal mediante cordocentesis a solicitud de la gestante.

En cuanto a la gravedad de la isoinmunización, el $77 \%$ de los casos fueron leves y el $23 \%$ graves. De las pacientes con anticuerpos antiKell con pareja Kell positiva, dos abortaron ( una de 8 semanas y otra a las 15 semanas de gestación), una tuvo un parto inmaduro de 23 semanas, cuatro no precisaron tratamiento fetal (en todas el neonato fue Kell negativo) y en cuatro la afectación fue grave (los neonatos fueron Kell positivo).

En todas las isoinmunizaciones se realizó un control ecográfico para valorar signos de anemia fetal, detectándose en dos casos ascitis, polihidramnios y derrame pericárdico. En todas ellas, se utilizó la medición Doppler del pico sistólico en la arteria cerebral media para estimar la anemia fetal. En relación al tratamiento, tres gestantes recibieron tratamiento con inmunoglobulinas intravenosas, no objetivándose ninguna reacción adversa. Debido a la evidencia de anemia fetal con la velocimetría Doppler, se realizaron transfusiones intrauterinas en tres pacientes. En la Tabla I, se pueden observar los controles velocimétricos de una de las pacientes. Se presentó una complicación grave durante la realización de una transfusión intravascular fetal, siendo necesario realizar una cesárea urgente tras una bradicardia fetal mantenida. También consideramos complicación de la terapéutica intrafetal el desencadenamiento del parto en la semana 28 de una de las gestantes, tras la realización de la transfusión intraútero.

Con respecto al pronóstico fetal, las gestantes con pareja Kell positiva e isoinmunizaciones leves, excepto aquellas que tuvieron un aborto, finalizaron la gestación a término y sin complicaciones. Todas las isoinmunizaciones graves, que no abortaron, precisaron finalizar la gestación antes del término: una en la semana 28 , de forma espontánea (aunque había recibido previamente, en dos ocasiones, transfusiones intraútero); otra, de forma espontánea en la semana 35 de gestación (aunque se le iba a inducir el parto al dia siguiente por aumento de resistencias vasculares en la ecografía-Doppler) y una tercera paciente al presentar una bradicardia mantenida tras la realización de transfusión fetal intraútero, en la semana 28. Por último otra paciente con alloinmunización grave, finalizó la gestación mediante cesárea (por antecedentes obstétricos), tras maduración pulmonar fetal con corticoides a las 32 semanas de gestación (Tabla II).

En cuanto a los cuidados pediátricos de los

Tabla I

TRANSFUSIÓN INTRAUTERINA: EVALUACIÓN DE LA VELOCIDAD MÁXIMA EN LA ARTERIA CEREBRAL MEDIA (ACM) PRE y POSTRANSFUSIONAL (CASO 5)

\begin{tabular}{|c|c|c|c|}
\hline $\begin{array}{l}\text { Edad gestacional } \\
\text { (semanas) }\end{array}$ & ACM previa & $\begin{array}{l}\text { Transfusión } \\
\text { intrauterina }\end{array}$ & ACM posterior \\
\hline 27 & $46,2 \mathrm{~cm} / \mathrm{s}$. Normal & No procede & No procede \\
\hline 29 & $44,5 \mathrm{~cm} / \mathrm{s}$. Normal & No procede & No procede \\
\hline 30 & $\begin{array}{l}60 \mathrm{~cm} / \mathrm{s} \\
\text { Hb previa: } 7,8 \mathrm{~g} / \mathrm{dl}\end{array}$ & $70 \mathrm{cc}$ & $29 \mathrm{~cm} / \mathrm{s}$ \\
\hline 31 & $\begin{array}{l}64 \mathrm{~cm} / \mathrm{s} \\
\mathrm{Hb} \text { previa: } 8,2 \mathrm{~g} / \mathrm{dl}\end{array}$ & $100 \mathrm{cc}$ & $36 \mathrm{~cm} / \mathrm{s}$ \\
\hline 32 & $51 \mathrm{~cm} / \mathrm{s}$. Normal. & No procede & $\begin{array}{l}\text { No procede. Se programa } \\
\text { cesárea en la semana } 32 \text {, } \\
\text { previa maduración pulmonar } \\
\text { con corticoterapia. }\end{array}$ \\
\hline
\end{tabular}


neonatos con isoinmunización grave, todos precisaron fototerapia y dos de ellos requirieron la administración de gammaglobulina intravenosa. En un caso fue necesario transfundir al recién nacido por anemización a los 5 días. Otro precisó paracentesis evacuadora.

La evolucion psicomotora de todos ellos a los 7 meses de vida fue normal (Tabla II).

\section{DISCUSIÓN}

La incidencia relativa de la isoinmunización antiKell ha aumentado en los últimos años debido al mayor número de transfusiones sanguíneas y a la disminución de la isoinmunización antiD provocada por la profilaxis de forma universal en las gestantes Rh negativas $(1,5)$.

Aunque existe la creencia de que el antiKell tiene una inmunogenicidad mucho menor que el antígeno responsable de la isoinmunización $\mathrm{Rh}$, en nuestra serie existe un $23 \%$ de isoinmunizaciones graves, cuyos fetos desarrollaron una anemia moderada a severa $(6,10)$.

Todas las isoinmunizaciones graves presentaban títulos de anticuerpos iguales o superiores a 256, sólo existe una paciente con titulaciones elevadas que desarrolló una isoinmunización leve. Por ese motivo en el caso del antiKell, las títulaciones de anticuerpos por sí solas no pueden ser un reflejo de la gravedad, aunque si pueden ser orientativas, pues titulaciones iguales o superiores a 256 al comienzo del segundo trimestre suelen ir asociadas a anemias graves. Las titulaciones intermedias son las que pueden tener una evolución más inesperada.

En nuestra serie, el $46 \%(12 / 26)$ de las pacientes tenía el antecedente de transfusión, que contradice la idea de otros autores que atribuyen este origen transfusional, a la mayoría de sus casos y corrobora el hecho de que muchos casos son inducidos durante la gestación (10). Pero de estas 12 pacientes con antecedentes de transfusión, en cuatro su pareja era Kell positivo, luego no podemos atribuir, en estos casos, la causa de la isoinmunización al antecedente de administración de hemoderivados. Dos de las pacientes que tenían en sus antecedentes la transfusión sanguínea abortaron en el primer trimestre, pero no podemos asumir que la isoinmunización antiKell fue la causa del aborto, teniendo en cuenta además, que sus titulaciones eran muy bajas. Existen pacientes en las que aparentemente no se encuentra la causa que provocó la isoinmunización. Pero ahondando en la anamnesis en la mayoría de los casos existían embarazos con parejas previas que habrían provocado la alloinmunización.

Tabla II

PRONÓSTICO FETAL EN LAS ISOMUNIZACIONES GRAVES: VIA DE FINALIZACIÓN DE LA GESTACIÓN

\begin{tabular}{|c|c|c|c|c|}
\hline Paciente & $\begin{array}{c}\text { Titulación } \\
\text { anticuerpos }\end{array}$ & $\begin{array}{l}\text { Tratamiento } \\
\text { prenatal }\end{array}$ & $\begin{array}{l}\text { Vía de finalización } \\
\text { de la gestación }\end{array}$ & Tratamiento postnatal \\
\hline 1 & 256 & $\begin{array}{l}\text {-Inmunoglobulinas } \\
\text {-Transfusión intraútero }\end{array}$ & $\begin{array}{l}\text { Cesárea urgente } \\
28 \text { semanas por } \\
\text { bradicardia tras } \\
\text { transfusión intraútero }\end{array}$ & $\begin{array}{l}\text { Fototerapia } \\
\text { Gamaglobulina } \\
\text { Transfusión sanguínea }\end{array}$ \\
\hline 2 & 256 & $\begin{array}{l}\text {-Inmunoglobulinas } \\
\text {-Transfusión intraútero }\end{array}$ & $\begin{array}{l}\text { Parto prematuro a } \\
\text { las } 28 \text { semanas }\end{array}$ & $\begin{array}{l}\text { Fototerapia } \\
\text { Paracentesis evacuadora }\end{array}$ \\
\hline 3 & 256 & $\begin{array}{l}\text { NO por interrumpirse } \\
\text { la gestación previamente } \\
\text { a iniciar el tratamiento }\end{array}$ & $\begin{array}{l}\text { Feto muerto intraútero } \\
\text { a las } 23 \text { semanas }\end{array}$ & --- \\
\hline 4 & 1024 & $\begin{array}{l}\text { NO por interrumpirse la } \\
\text { gestación previamente } \\
\text { a iniciar el tratamiento }\end{array}$ & Aborto primer trimestre & --- \\
\hline 5 & 512 & Transfusión intraútero & $\begin{array}{l}\text { Cesárea programada en } \\
\text { semana } 32 \text { (tras maduración } \\
\text { pulmonar) }\end{array}$ & $\begin{array}{l}\text { Fototerapia } \\
\text { Gamaglobulina }\end{array}$ \\
\hline 6 & 256 & Inmunoglobulinas & Parto espontáneo semana 35 & Sin información \\
\hline
\end{tabular}


Cuando el padre es heterozigoto para el antígeno Kell o el grupo paterno se desconoce, es importante conocer precozmente el grupo fetal, pues sólo en los casos con feto Kell positivo, la isoinmunización podrá ser grave y así podremos aconsejar a la pareja sobre el pronóstico y tranquilizar a aquellas gestantes cuyo feto sea Kell negativo. La posibilidad de determinar el ADN fetal en sangre materna, en los casos con progenitor heterozigoto, se realiza a comienzos del segundo trimestre de forma no invasiva y eficaz y nos permite obtener una información muy valiosa de cara al tratamiento y evolución del feto, aunque todavía sólo es posible realizarla en muy pocos laboratorios $(7,9)$.

La determinación del pico sistólico (VMax -ACM) fue útil para valorar la gravedad de la anemia fetal, sin utilizar una técnica invasiva y poder indicar el tratamiento transfusional. Por lo que la evolución de las técnicas de diagnóstico prenatal ha hecho posible un nuevo enfoque para este tipo de patologías (9).

Existe controversia en cuanto a la eficacia de la utilización de gammaglobulinas intravenosas, pero se optó por esta terapéutica en los casos en que los títulos de anticuerpos estaban muy elevados y la escasa edad gestacional impedía recurrir a la transfusión intrauterina. Su objetivo es retrasar el desarrollo de anemia grave y poder alcanzar edades gestacionales en las que nos podamos plantear otras opciones terapéuticas. La gammglobulina actúa disminuyendo la sintesis y el paso transplacentario de anticuerpos y bloqueando los receptores de los macrófagos fetales (4).

El tratamiento de la anemia fetal de forma intrauterina es eficaz, aunque en ocasiones requiere repetirse varias veces y puede presentar complicaciones, como la bradicardia fetal, la muerte fetal intraútero (1-3\% sin signos hidrópicos y hasta un $15 \%$ con ellos), la posterior presencia de amenaza de parto prematuro o el desarrollo de infecciones intraútero.

Algunos casos son detectados por primera vez, en el momento del parto, cuando se realiza la determinación del grupo sanguíneo y escrutinio de anticuerpos irregulares en la sangre materna. Son recién nacidos sin repercusión hemodinámica por esta isoinmunización y su hallazgo, por tanto, no tendrá repercusión en esta gestación pero sí pudiera tenerlo en las venideras. Es relevante recalcar la importancia de la determinación del escrutinio de anticuerpos irregulares en todas las gestantes tanto Rh positivas como negativas, para poder determinar este tipo de isoinmunizaciones, ya que se esta objetivando con el movimiento inmigratorio la aparición de isoinmunizaciones graves no controladas. No se han detectado casos de aplasia postnatal prolongada en los neonatos afectos, contrariamente a lo argumentado por otros autores en la literatura (12).

El manejo actual de esta isoinmunización, posibilita a estas gestantes ser estudiadas y tratadas de forma satisfactoria. Sin embargo, son necesarios más estudios que permitan obtener una mayor información sobre las peculiaridades de la isoinmunización antiKell.

\section{BIBLIOGRAFÍA}

1. Moise KJ Jr. Non-anti-D antibodies in red-cell alloimmunization. Eur J Obstet Gynecol Reprod Biol 2000;92:7581.

2. Reid M, Lomas Francis C. The blood group antigen. Facts Book. $2^{\mathrm{a}}$ ed. London: Elsevier Academic Press, 2004;225-63.

3. Vaughan JI, Manning M, Warwick RM, Letsky EA, Murray NA, Roberts IA. Inhibition of erythroid progenitor cells by anti-Kell antibodies in fetal alloimmune anemia. N Engl J Med 1998;338:798-803.

4. Babinszki A, Lapinski RH, Berkowitz RL. Prognostic factors and management in pregnancies complicated with severe kell alloimmunization: experiences of the last 13 years. Am J Perinatol1998;15:695-701.

5. Leggat HM, Gibson JM, Barron SL, Reid MM. Anti-Kell in pregnancy. Br J Obstet Gynaecol 1991;98:162-5.

6. Freire-Lizama T, Oepkes D. Management of Kell alloinmunized pregnancies. Fetal Mater Med Rev 2002;13:87-102.

7. Bennet PR, Le Van KimColin Y, Warwick RM, CherifZahar B, Fisk NM, Cartron JP. Prenatal determination of fetal RhD type by DNA amplification. N Engl J Med 1993;329:607-10.

8. Lo YM, Hjelm NM, Fidler C, Sargent IL, Murphy MF, Chamberlain PF, Poon PM, Redman CW, Wainscoat JS. Prenatal diagnosis of fetal RhD status by molecularanalysis of maternal plasma. $\mathrm{N}$ Engl $\mathrm{J}$ Med 1998;339:1734-8.

9. Harper TC, Finning KM, Martin P, Moise KJ Jr. Use of maternal plasma for noninvasive determination of fetal RhD status. Am J Obstet Gynecol 2004;191:1730-2.

10. Santiago JC, Ramos-Corpas D, Oyonarte S, Montoya F. Current clinical management of anti-Kell alloimmunization in pregnancy. Eur J Obstet Gynecol Reprod Biol 2008;136:151-4.

11. Moise KJ Jr. Management of rhesus alloinmunization in pregnancy.Obstet Gynecol 2008;112:164-76.

12. Collinet $P$, Subtil D, Puech F, Vaas P. Successful treatment of extremely severe anemia due to Kell alloinmunization. Obstet Gynecol 2002;100 (5pt2):1102-5.

13. Gariod S, Brossard $Y$, Poissonier MH, Vuilliez B, Deutsch V, Jouk PS, Pons JC. Kell alloimmunization in pregnancy. J Gynecol Obstet Biol Reprod (Paris) 2004;33:637-48. 